\title{
Optimal Decision on Landside Operations and Truck Tour of a Container Terminal
}

\author{
Junmin Yi \\ School of Economics and Management, Xiamen University of Technology, Xiamen, China
}

\section{Email address:}

yijunmin@xmut.edu.cn

\section{To cite this article:}

Junmin Yi. Optimal Decision on Landside Operations and Truck Tour of a Container Terminal. Science Journal of Business and Management. Vol. 5, No. 2, 2017, pp. 64-69. doi: 10.11648/j.sjbm.20170502.14

Received: January 18, 2017; Accepted: March 2, 2017; Published: March 10, 2017

\begin{abstract}
In modern container transportation, the containers transshipment between the quayside and landside plays a key role in the efficiency of a container terminal. From the perspective of logistics, port operations are determined by the port facilities, space and running time, and a focus on container movement within the terminal will draw more attention on the operational efficiency of port transportation and handling of the terminal. By analyzing the elements of the system operations, a mathematical model is setup to solve container movement by truck routing and yard layout. With the model and the instance data from a container terminal, the container truck tour and optimization problem is well settled, and the model's feasible application is discussed.
\end{abstract}

Keywords: Container Terminal, Operations, Truck, Transportation, Route

\section{Introduction}

Containerization is the revolution of transportation in the 20th century. Nowadays container transportation plays a key role in the world trade and economy of port cities [1]. According to Drewry Shipping Consultants, the annual container traffic has increased more than six times since 1990, and in 2015 the global container transport reaches 1,777 million TEUs with a total capacity of 2.19 million TEUs by all container carriers. For a typical cargo liner, it is critical to have a high throughput of ships at the port. This requires that the time spent on each ship visit is as small as possible and consequently, modern container port operation requires an efficient operation of the port facilities. In those ports, the container terminals (CT) are critical facilities, where cargo containers are transshipped between ships and land vehicles. A container terminal has quayside and land side areas, while the quayside with loading and unloading of ships, and the landside where containers are loaded and unloaded on/off vehicles [2]. The $\mathrm{CT}$ operators as port service providers directly serve the container line operators (carriers); they are of particular importance for container transportation of a port, and they also have leading service connection with container yards, stevedore companies and haulers [3].

In the landside of a $\mathrm{CT}$, there are storage yards for the stacking of export/import containers, and the transshipment of containers between ships and yards. Trucks with checked export containers arrive at the terminal's in-gate. Data of the containers are fed in the terminal's information system. Trucks then drive to storage yard to unload the export container waiting for incoming vessel.

With modern quayside and landside cranes and other equipment in a container terminal, a vessel visits the terminal just in several hours to unload import containers and to load export containers. The import containers unloaded from the vessel also enter the storage yards for shot time stacking. In such a short time, the transport from quayside to landside is very busy and it plays a key role in the total efficiency of the CT. However, the organization of the transport inside the terminal for the vessel visit is a complex problem, those questions such as the block assignment, the truck route for containers need to be considered systematically and optimally to achieve CT operational efficiency.

Thus it is necessary and important to examine the transshipment operations between landside storage yards based on the CT layout and configuration. In this paper, we quantitatively study the $\mathrm{CT}$ transshipment operations with a case of a key port in southeast China. 


\section{Literature Review}

Container transportation has a vast development in the last century, as the key infrastructure of container transportation, the number and capacity of seaport container terminals has increased and will increase in the future. However, in the short term CT operators have to handle increased cargo amounts at their terminals with given limited capacity. High operating costs for ships and container terminals as well as high capitalization of ships, containers and port equipment demand the reduction of unproductive times at port. To balance the high concentration of activities and control the traffic congestion of trucks, cranes and other handling equipment in the yard, many related studies have been presented. Thus it will encourage port authorities and CT operators to redesign the landside buffering and handling of containers to more efficiency, rather to keep up with higher cargo amounts than to decrease costs [4].

The super ordinate goal is to reduce the time for the discharging and loading process of a ship [3]. Speed and efficiency are very important in the global transport of goods, not only for the carrier but also for a terminal, since the competition among container terminals has increased [5].

A typical container liner carrier operates several container vessels serving many ports. The problem of efficiently operating such a line fleet is composed of several sub problems, among them finding an optimal fleet size and fleet routing, the problem of efficiently transferring the containers to and from the ships, and the problem of an efficient utilization of the ship's capacity. Port efficiency and ship utilization efficiency largely depend on the way in which containers are stored in the ports and inside the ships [6].

On the other side, in a typical layout of a CT system (Figure 1), quayside and landside are seamlessly configured and operated coordinately to achieve its operational goals. While [7] provides a comprehensive survey of the state-of-the-art of operations at a container terminal (see Figure 2 for illustration) as well as methods for their optimization, and [8] considers yard operations paradigms and developments systematically with review and proposal a formal classification scheme for storage yard operations. Empty containers are needed at the sheds for stuffing purposes and imbalances; they are prepared for ship, train and truck loading and have to be transported to the respective yard or transition area. A reorganization of the yard has to be performed for additional transports and their characteristic.

However, to speed the discharging and loading process of a vessel from the quayside, the landside operations and efficiency in the CT system should be considered also. In the landside, there are storage yard to buffer import and export container movements, the yard layout, block configuration, container assignment and truck routing are key factors to affect the operations and efficiency. The outbound or export containers are stored in the container stack yard in the landside of the terminal. Containers are stored in the yard in a block configuration.

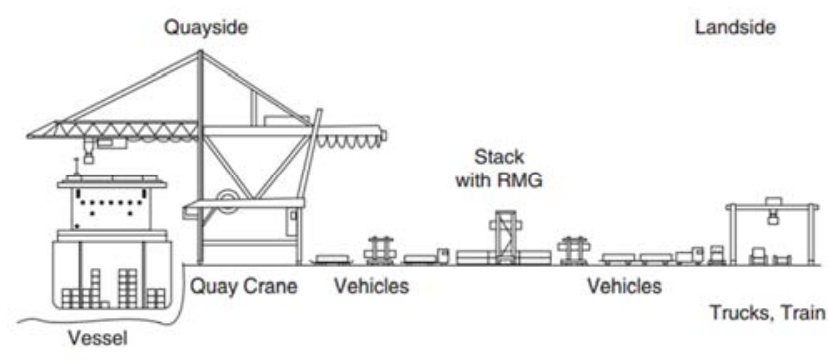

Figure 1. Container terminal system (schematic side view) [6, p. 13].

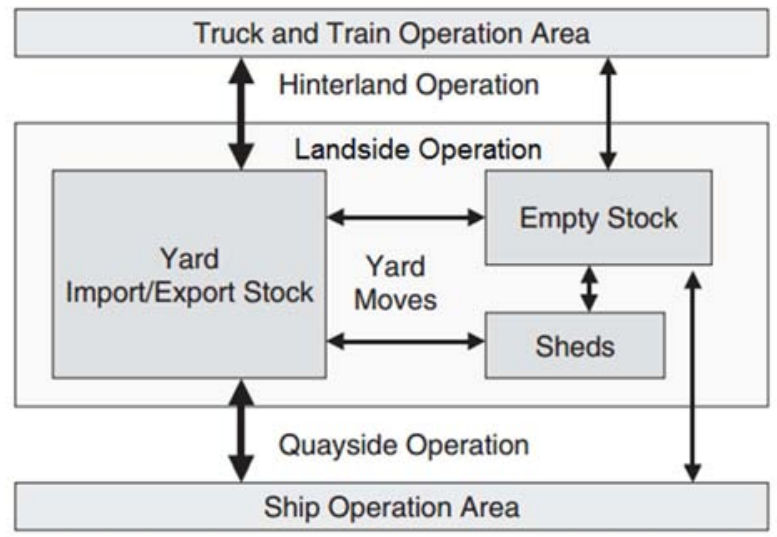

Figure 2. Operations of a seaport container terminal and flows [6].

The efficiency of loading operations in CTs is highly dependent upon the smooth flow of containers to and from the quayside and landside area. A dysfunctional material flow pattern results in congestion and, ultimately, in increased container handling costs. Past studies have identified the container's operation as the bottleneck in the material flow during the loading operation [9].

In a busy $\mathrm{CT}$, the loading and unloading processes have to be considered at the same time. The need to handle large volumes of container traffic and the scarcity of land in the CT landside area pose serious challenges for the port operator to provide efficient services. The container loading and unloading activities in a $\mathrm{CT}$ are usually concentrated and inevitably happen at the same time. This makes the yard planning problem much more challenging compared to port planning for general terminals where loading and unloading activities can be considered independently by having different dedicated storage areas for import and export activities [10].

Martin et al. [11] have developed a heuristic for load planning of container ships while taking the efficiency of the gantry crane operations into account. Their results show that significant changes in the operational efficiency of the cranes are possible by using a good heuristic. An iterative search algorithm [12] integrates a container transfer model and a container-location model to determine an optimal storage strategy and handling schedule. Also [4] improves the efficiency in the storage yard through scheduling the storage and retrieval of containers. 
For these transport flows, various optimization models such as vehicle routing problem have been proposed to handle these problems [13]. A optimal time model is setup and solved by [14] with total truck time and crane time minimized by the parallel loading and unloading process, and maximum mileage saving is achieved after iterations. Optimization has to be very flexible and fast, online optimization is necessary [15]. Objectives at the truck operations area are minimization of empty distances and/or travel times. Empty distances can be minimized if transports of export containers from the transition point to the yard are combined with transports of import containers from the yard to the interchange point [16].

Generally these kinds of transports are not as time critical as those for the ship or truck operation. Therefore, terminals try to execute them at times of less workload. The objective is to minimize (empty and loaded) travel times or total travel distances. In general, two categories of optimization models: transportation models or routing/scheduling models dominate the research of $\mathrm{CT}$ optimization.

\section{A Transportation Model for Truck Tours}

In most container terminals, vessels visit regularly by the schedule of container lines [17]. And several internal trucks are used to transfer containers within the terminal. When a vessel arrives at a berth, a container is grasped by the quay crane and loaded to a truck, then transported to the yard. Then after unloading the container, the truck back to the berth empty or with an export container to be stowed into the vessel. This process forms a truck tour in the container terminal. To minimal the tour, it forms one type of the CT truck route optimization problems defined by [18].

In our model, bearing the idea of simultaneous process of loading and unloading, the tour is a closed path between a quay crane, next unloading block and/or reloading block, and finally the quay crane again. With continues tours consequently by one and usually more trucks, the container loading and unloading job of a vessel visit can be finished smoothly and efficiently. And in our transportation model, questions below are focused:

- The block assignment for import and export containers;

- The truck tours for import containers;

- The truck tours for export containers;

- The truck tours with empty backhaul because of imbalance.

\subsection{Model Assumption}

When a vessel visits a $\mathrm{CT}$ which is neither the starting nor the ending port of a container line service, there are some import containers to be unloaded from the ship to the CT and some export containers to be loaded into the ship. Then with the given layout and configurations of the $\mathrm{CT}$, data can be collected for the model assumption.

Let $M$ to be the total containers imported to the stacking yard and $N$ the total exported containers, while $E_{i}$ is the export containers stacked in yard block $i$, and $I_{i}$ is the imported containers that can be stacked in block $i(i=1,2, \ldots$, $n)$. If the exported and imported containers are stacked in separated blocks, then $E_{i}$ is 0 in an import container block and $I_{i}$ is also 0 in an export container block.

\subsection{Model Formula}

In our model, to achieve the operational efficiency, the decisions variables $x_{i j}$ define the truck tour, in which $x_{i j}$ containers will be unloaded in block $i$ and then the same number of containers be loaded in block $j$ toward the quay.

And the objective is to set the minimal traveling distance of all vehicle moving containers between the yard blocks and the quayside.

Thus, the objective function is:

$$
\operatorname{MinZ}=\sum_{i=1}^{n} \sum_{j=1}^{n} x_{i j}\left(S_{i}+S_{j}+S_{i j}\right)
$$

Subject to

$$
\begin{aligned}
& \sum_{i=1}^{n} x_{i j} \geq E_{i}, j=1,2, \ldots, n \\
& \sum_{j=1}^{n} x_{i j} \leq I_{i}, i=1,2, \ldots, n \\
& \sum_{i=1}^{n} \sum_{j=1}^{n} x_{i j} \leq \max (M, N) \quad \forall i, j \\
& x_{i j} \geq 0 \quad \forall i, j
\end{aligned}
$$

Here constraint (2) restricts that the import containers to be stacked in block $i$ will be less than the total capacity of import containers in that block. There will be an imbalance of import and export containers if the accumulated import containers from block $j$ are larger than those exported, thus the vehicle will return to the quayside without container, vise visa. Constraint (3) defines all export containers to be trucked to the quayside and the handling job is finished. Constraint (4) ensures that the quantity of moved containers is less than the containers to be load or unload for a vessel visiting the container terminal. And constraints (5) define our decisions variables. While $S_{i}$, is the distance from block $i$ to quay. $S_{j}$ is the depth of block $j$, and $S_{i j}$ are the rectangular distances (real route distances) from block $i$ to block $j$ respectively.

This model belongs to the transportation model category in general, and it can be solved by those Simplex based method.

\section{CT Case Study and Discussion}

\subsection{Container Terminal Background}

XSCT is a modern container terminal jointly operated by the local port operator and a world famous container operator with an investment of 1.68 billion RMB and opening on September 6th, 2007. XSCT is strategically located at the southeast of Haicang district, which is the main channel of 
Xiamen Port in southeast China. There are three berths for the latest modern container vessel with a capacity of 18,000 TEU or other large ships with tonnage of 150,000 tons. There are 1246 meters of quay length in the terminal with -17 meters draft alongside, and the CT has 1,800,000 TEUs annual capacity. With specifications listed in table 1 , the terminal has the capacity to accommodate three $15,000 \mathrm{TEU}$ vessels simultaneously.

Table 1. Specifications of XSCT.

\begin{tabular}{ll}
\hline Items & Values \\
\hline Berth & 1246 meters for three vessels simultaneously \\
Terminal land depth & $1400 \mathrm{~m}$ \\
Quayside depth & $520 \mathrm{~m}$ \\
Terminal land area & $643637 \mathrm{~m}^{2}$ \\
Stacking yard area & $353300 \mathrm{~m}^{2}$ \\
Stacking blocks & 8 for export/import, 1 for empty \\
Grounded empty storage & 13992 TEUs \\
Total yard slots & 60955 TEUs \\
Quay cranes & 10 \\
Stacking cranes & 18 (RTG) \\
\hline
\end{tabular}

The vital economic development in Southeast China for both import and export demands, superior geographical conditions, world-class handling equipment and proficient employees support the $\mathrm{CT}$ project to be the leading container terminal in the Greater China, and it strive to be the best international container terminals. And its operations should be also tuned for this objective.

\subsection{Data and Layout}

In this case, the detail information of the CT is examined to achieve operational improvements.

The storage yard of XSCT is further divided into 8 stacking blocks for holding import or export freight containers, as shown in Figure 3.

While Table 1 lists the main specifications of XSCT. And based on the terminal layout, the distances between each blocks and quay are shown in Table 2 .

And from the operational dataset, for example, a particular vessel visit instance, the required containers and initial assignments are listed in Table 3 . The total import containers $M$ is 1284 , and export containers $N$ is 1160 .

Table 2. Distance between blocks (meters).

\begin{tabular}{llllllllll}
\hline $\mathbf{i}$ & $\mathbf{Q u a y}$ & $\mathbf{A}$ & $\mathbf{B}$ & $\mathbf{C}$ & $\mathbf{D}$ & $\mathbf{E}$ & $\mathbf{F}$ & $\mathbf{G}$ & $\mathbf{H}$ \\
& $\mathbf{S}_{\mathbf{i}}$ & $\mathbf{S}_{\mathbf{i} 1}$ & $\mathbf{S}_{\mathbf{i} 2}$ & $\mathbf{S}_{\mathbf{i} 3}$ & $\mathbf{S}_{\mathbf{i} 4}$ & $\mathbf{S}_{\mathbf{i} 5}$ & $\mathbf{S}_{\mathbf{i} 6}$ & $\mathbf{S}_{\mathbf{i} 7}$ & $\mathbf{S}_{\mathbf{i} 8}$ \\
\hline $\mathrm{A}$ & 25 & 0 & & & & & & & \\
B & 25 & 25 & 0 & & & & & & \\
$\mathrm{C}$ & 25 & 290 & 25 & 0 & & & & & \\
D & 25 & 525 & 260 & 25 & 0 & & & & \\
E & 25 & 750 & 485 & 250 & 25 & 0 & & & \\
F & 305 & 985 & 720 & 485 & 20 & 15 & 0 & & \\
G & 305 & 760 & 495 & 20 & 15 & 25 & 25 & 0 & \\
H & 305 & 525 & 65 & 15 & 20 & 250 & 250 & 25 & 0 \\
\hline
\end{tabular}

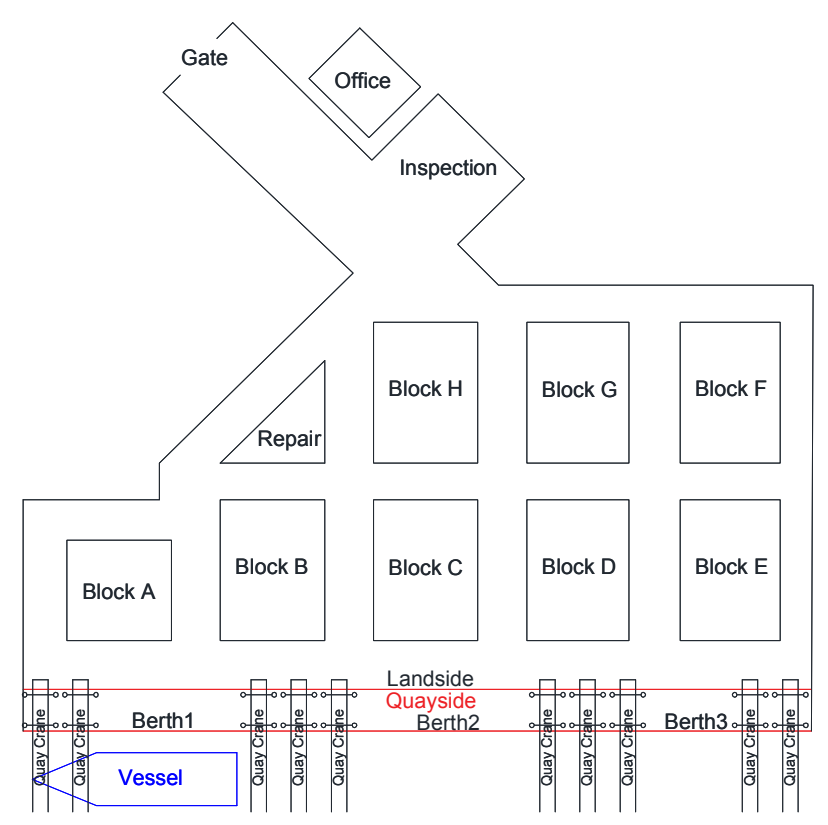

Figure 3. Layout of XSCT.

Table 3. Instance of import and export containers for blocks (TEU).

\begin{tabular}{lllllllll}
\hline Blocks & A & B & C & D & E & F & G & H \\
\hline Import & 210 & 180 & 209 & 314 & 51 & 94 & 166 & 60 \\
Export & 100 & 170 & 321 & 231 & 46 & 99 & 106 & 87 \\
\hline
\end{tabular}

\subsection{Solutions and Results}

Thus, input these values into our model, a result will be generated by CPLEX. The objective value is 201925.0, and the results of variables are listed in Table 4.

Table 4. Result of variables.

\begin{tabular}{llllllllll}
\hline & $\mathbf{A}$ & $\mathbf{B}$ & $\mathbf{C}$ & $\mathbf{D}$ & $\mathbf{E}$ & $\mathbf{F}$ & $\mathbf{G}$ & $\mathbf{H}$ & $\boldsymbol{I}_{\boldsymbol{i}}$ \\
\hline $\mathrm{A}$ & 100 & 110 & 0 & 0 & 0 & 0 & 0 & 0 & 210 \\
$\mathrm{~B}$ & 0 & 60 & 120 & 0 & 0 & 0 & 0 & 0 & 180 \\
$\mathrm{C}$ & 0 & 0 & 201 & 0 & 0 & 0 & 0 & 8 & 209 \\
$\mathrm{D}$ & 0 & 0 & 0 & 231 & 0 & 0 & 64 & 19 & 314 \\
$\mathrm{E}$ & 0 & 0 & 0 & 0 & 46 & 5 & 0 & 0 & 51 \\
$\mathrm{~F}$ & 0 & 0 & 0 & 0 & 0 & 94 & 0 & 0 & 94 \\
$\mathrm{G}$ & 0 & 0 & 0 & 0 & 0 & 0 & 42 & 0 & 42 \\
$\mathrm{H}$ & 0 & 0 & 0 & 0 & 0 & 0 & 0 & 60 & 60 \\
$E_{\boldsymbol{i}}$ & 100 & 170 & 321 & 231 & 46 & 99 & 106 & 87 & 1160 \\
\hline
\end{tabular}

From Table 4, the data can be further applied to the import container storage. We ensure that 210 import containers to block A, and 180 to B, 209 to C, 314 to D, 51 to E, 94 to E, 42 to $\mathrm{G}$, and 60 to $\mathrm{H}$.

\subsection{Result Analysis and Discussion}

The routes for export containers from stacking blocks to quayside are as follows:

- Tour 1. In Block A, 100 import containers moved from quayside to block $\mathrm{A}$, then unloading and staging, while 100 export containers is then loaded into the trucks and toward quayside. In short it is a Quay-Block A-Block 
A-Quay path. Indeed it is 100 consequent tours for trucks along this path.

- Tour 2. In Block B with total 170 export containers, while 110 containers follow the Quay-Block A-Block B-Quay path, and 60 by Quay-Block B-Block B-Quay path.

- Tour 3. In Block C with total 321 export containers, while 120 containers follow the Quay-Block B-Block C-Quay path, and 201 by Quay-Block C-Block CQuay path.

- Tour 4. In Block D with total 231 export containers, 231 containers all follow the Quay-Block D-Block D-Quay path.

- Tour 5. In Block E with total 46 export containers, all 46 containers follow the Quay-Block E-Block E-Quay path.

- Tour 6. In Block F with total 99 export containers, while 5 containers follow the Quay-Block E-Block F-Quay path, and 201 by Quay-Block F-Block F-Quay path.

- Tour 7. In Block G with total 106 export containers, while 64 containers follow the Quay-Block D-Block G-Quay path, and 42 by Quay-Block G-Block GQuay path.

- Tour 8. In Block $\mathrm{H}$ with total 87 export containers, while 8 containers follow the Quay-Block C-Block HQuay path, 19 by Quay-Block D-Block H-Quay path, and 60 by Quay- Block H-Block H-Quay path.

In the situation of parallel loading and unloading process, the total travel distance can't be minimal if the import containers are assigned to a block by "adjacent" principle. From our results, Block A which is closed to quay and remote Block $G$ are not fully assigned with containers because of varied distances between different container stacking blocks.

In the process of container transport, the $M, N$ values which a vessel visits the terminal can be reached in advance through the Booking Confirmation. Thus our model can be run each time before the vessel visit and can guide the block assignment based on their capacity or adjusting the block capacity on site. Our objective is to achieve total minimal travel distance, in other word; the working efficiency can be improved by this way in some significant extent.

Since the berths can hold three vessels in the same time, however, if three vessels visit the terminal simultaneously, the $M, N$ value of our model will be the sum of the import /export containers to be handled for these ships. But it is complicated for the block assignment because the containers of each ship must be clarified and distinguished in the stacking blocks. Further variables assignment is needed for this situation.

\section{Conclusion}

There are many optimal problems for the operations of container terminals. In this paper we studied a specific container flow between the quayside and landside in a container terminal with given yard layout and configurations. By examining different optimal models proposed for container terminal optimization both on quayside and landside, we setup our specific transportation model for the transshipment of containers within the terminal. The solutions and suggest applications are proposed based on the real data from the CT's layout and operations.

Our study helps the terminal to improve its operations and may encourage container terminal industry to realize optimal and reasonable operations. However, the operational efficiency is decided by multiple factors and further details on operations can be examined for better implementation.

\section{Acknowledgments}

The authors wish to thank the anonymous referees whose careful reading and comments helped to greatly improve the paper. Also, Yuanyuan Lin's discussion and help is also acknowledged. This work is partially supported by NSFC Research Grant 71371162 and the Fujian Provincial Natural Science Foundation (Grant No. 2014J01271).

\section{References}

[1] W. K. Talley, "Port Economics," New York: Routledge Press, ch. 10, pp. 181-184, 2009.

[2] J. C. Fransoo and C.-Y. Lee, "The critical role of ocean container transport in global supply chain performance," Production and Operations Management, vol. 22, no. 2, pp. 253-268, 2013.

[3] R. Stahlbock and S. Voß, "Operations research at container terminals: a literature update," OR Spectrum, 30 (1): 1-52, 2007.

[4] I. F. A. Vis and R. de Koster. "Transshipment of containers at a container terminal: An overview," European Journal of Operational Research, 147 (1): 1-16, 2003.

[5] R. Stahlbock and S. Voß, "Vehicle Routing Problems and Container Terminal Operations - An Update of Research," in B. Golden et al. (eds.), The Vehicle Routing Problem, Berlin: Springer, 2008, pp. 551-589.

[6] A. Narasimhan and U. S. Palekar, "Analysis and Algorithms for the Transtainer Routing Problem in Container Port Operations," Transportation Science, 36 (1): 63-78, 2002.

[7] D. Steenken, S. Voß, and R. Stahlbock, "Container terminal operations and operations research - a classification and literature review," OR Spectrum, 26: 3-49, 2004.

[8] H. J., Carlo, I. F. A., Vis, and K. J. Roodbergen, "Storage yard operations in container terminals: Literature overview, trends, and research directions," European Journal of Operational Research, vol. 235, no. 2, pp. 412-430, 2014.

[9] Y. G. Chung, S. U. Randhawa, and E. D. McDowell, "A simulation analysis for a transtainer-based container handling facility," Computer and Industrial Engineering, 14 (2): 113125, 1985.

[10] X. Jiang, L. H. Lee, E. P. Chew, Y. Han, and K. C. Tan, “A container yard storage strategy for improving land utilization and operation efficiency in a transshipment hub port," European Journal of Operational Research, 221, 64-73, 2012. 
[11] G. L. Martin, S. U. Randhawa, and E. D. McDowell, "Computerized container-ship load planning: A methodology and evaluation," Computer and Industrial Engineering, 14 (4): 429-440, 1988.

[12] E. Kozan and P. Preston, "Mathematical modeling of container transfers and storage locations at seaport terminals," OR Spectrum, 28, 519-537, 2006.

[13] R. van der Meer. "Operational Control of Internal Transport". Phd Dissertation, Erasmus University, Rotterdam, The Netherlands, 2000 .

[14] M. J. Ji, Z. H. Jin, "A scheduling optimization of trucks and quay cranes coordination in container terminals," Journal of Fudan University, Natural Sciences, 2007, (8): 476-480. [In Chinese]
[15] M. Vidovic, T. Baltacioglu, O. Yurt, and G. " Ozkan, "Matching algorithms for the vehicle routing in containers delivery and collecting problems," In Proc. of 7th Balkan Conf. on Operational Research (BACOR 05), Constanta, Romania, May 25-28, 2005.

[16] Y. M. Park and K. H. Kim, "A scheduling method for berth and quai cranes," OR Spectrum, 25 (1): 1-23, 2003.

[17] T. Notteboom and J.-P. Rodrigue, "The corporate geography of global container terminal operators," Maritime Policy \& Management, 39 (3): 249-279, 2012.

[18] Vis, I. F. A. and K. J. Roodbergen, "Scheduling of container storage and retrieval," Operational Research, 57 (2): 456-467, 2009. 